\title{
PROCESSO CONTÍNUO PARA FERMENTAÇÕES INDUSTRIAIS $\left({ }^{1}\right)$
}

Paul Kolachov, diretor de pesquisas; LE RoY A. Smith, assistente, laboratbrio de fermentação: H. Frederick Willukie, ince-presidente, Joseph E. Seagram \& Sons, Inc., Louisville, Kenlucky, U.S.A.

\section{1 - INTRODUÇĀO}

O emprêgo do processo contínuo para os diversos tipos de fermentaçбes industriais tem encontrado grande aceitação, e, sem dúvida alguma, será utilizado em escala cada vez maior no futuro. Sòmente nestes últimos anos o processo adquiriu importância na produção de álcool e de fermento alimentício (food yeast), a partir de substratos especializados, tais como os resíduos sulfíticos da fabricação de papel e a madeira hidrolisada (1 a 16). Muitos outros substratos têm sido investigados com o fito de verificar a possibilidade de serem utilizados em processos contínuos para obtenção de produtos diversos. Entre os substratos que têm sido experimentados como matéria-prima para produção de álcool e de fermento, podemos citar os resíduos da indústria de suco de laranja, o melaço de laranja e os resíduos da indústria de conservas de frutas (17 a 21). O sôro do leite vem sendo usado num processo contínuo para produção de ácido láctico $(22,23)$. Verificou-se também que o agente patogênico Brucella suis Huddleson pode ser obtido em quantidade apreciável e com bastante segurança por meio de um processo contínuo para sua multiplicação (24).

Grande parte das pesquisas realizadas em nosso laboratório tem por objetivo o desenvolvimento de um processo contínuo para produção de álcool e de enzimas segregadas por fungos. Pesquisamos também a possibilidade e viabilidade de um processo contínuo para produção de penicilina. No 4. ${ }^{\circ}$ Congresso Internacional de Microbiologia, realizado em Copenhague, em 1947, apresentamos um relato sôbre a produção de álcool etílico a partir de mostos de cereais hidrolisados com ácido mineral, empregando um processo contínuo de fermentação. Relatamos ainda um processo contínuo para multiplicação de fermento em destilaria, bem como para as diversas operaçôes na produção de álcool de cereais sacarificados por ação enzimática, excetuando-se a operação de fermentação que continuava a ser pelo processo intermitente.

$O$ presente trabalho tem por escopo relatar os resultados que obtivemos em nossas pesquisas com outros tipos de fermentação, empregando um processo contínuo.

(1) Trabalho apresentado so 5.0 Congresso Internacional de Microbiologia, realizado no Rio de Janeiro, Brasil, de 17 a 24 de agôsto de 1950, e traduzido e adaptado pelo engenheiro agrônomo Ciro $G$. Teixeira, Instituto Agronónico de Campinas, ex-membro do Seagram Internationgl Fellowship Program. 


\section{2 - PROCESSO CONTINUO PARA PRODUÇÃO DE PENICILINA}

Estudamos a possibilidade de substituir o processo intermitente (batch process) pelo processo contínuo em fermentações mais complexas como é o caso da produção de penicilina (25). Não visamos obter maior rendimento ou reduzir o período de fermentação. $O$ objetivo primário foi o de verificar se seria possível manter condiçóes uniformes e invariáveis durante o processo de operação contínua. Procedeu-se do seguinte modo: colocou-se na dorna o meio de cultura comumente usado pela indústria para a produção de penicilina pelo processo intermitente. Êste meio consiste em $3 \%$ de concentrado de água de lavagem do milho (corn steep solids), $3 \%$ de lactose e $1 \%$ de carbonato de cálcio. Após a esterilização, o meio é semeado com $5 \%$ (calculados sôbre o volume total do meio de cultura existente na dorna) de cultura pura de Penicillium chrysogenum Thom, estirpe Q 176 da Universidade de Wisconsin. Deixa-se o fungo multiplicar durante 48 horas, a fim de permitir um bom desenvolvimento micelial. Inicia-se agora a operação contínua, retirando-se parte do meio de cultura da dorna e adicionando-se igual quantidade de meio de cultura esterilizado. Esta operação é realizada de modo que, num período de 48 horas, seja retirado um volume de produto fermentado igual ao volume total do meio de cultura existente na dorna, isto é, o ciclo total é de 48 horas. Depois de cada 12 horas de operação contínua, é adicionado à dorna $0,01 \%$ de ácido fenilacético. Estas experiências realizadas mostraram que o meio de cultura utilizado no processo intermitente para produção de penicilina não era adequado para uso no processo contínuo, visto não ter sido possível manter condições uniformes durante a operação contínua (fig. 1). Verifica-se que, após 48 horas de operação contínua, a capacidade para produzir penicilina decresce gradualmente, ao passo que o $\mathrm{pH}$ tende a se elevar. Entretanto, quando se adicionaram ao meio de cultura já descrito $0,5 \%$ de glicose, foi possível a manutenção de condições uniformes durante a operação contínua quando se trabalhou com um ciclo de operação contínua não muito longo, isto é, cêrca de 96 horas em operação contínua (fig. 1). Após operar durante 48 horas contìnuamente, observa-se que a capacidade para produção de penicilina se mantém constante. $\mathrm{O}$ pH do meio de cultura conserva-se também constante. Estas experiências preliminares demonstraram que é possível o emprêgo de um processo contínuo para produção de penicilina. Atualmente, estão sendo realizados estudos a fim de averiguar a possibilidade de ampliar o período de operação contínua, bem como tentar aumentar o rendimento em penicilina e reduzir o ciclo de fermentação.

\section{3 - ENZIMAS PRODUZIDAS POR FUNGOS}

Continua a ser objeto de investigações intensivas em nosso laboratório, o aperfeiçoamento de processos para produção contínua de enzimas amilolíticas, em culturas submersas de fungos (26). No trabalho apresentado ao $4 .^{\circ}$ Congresso Internacional de Microbiologia, apresentamos resultados obtidos nas pesquisas preliminares sôbre a produção de enzimas amilolíticas 


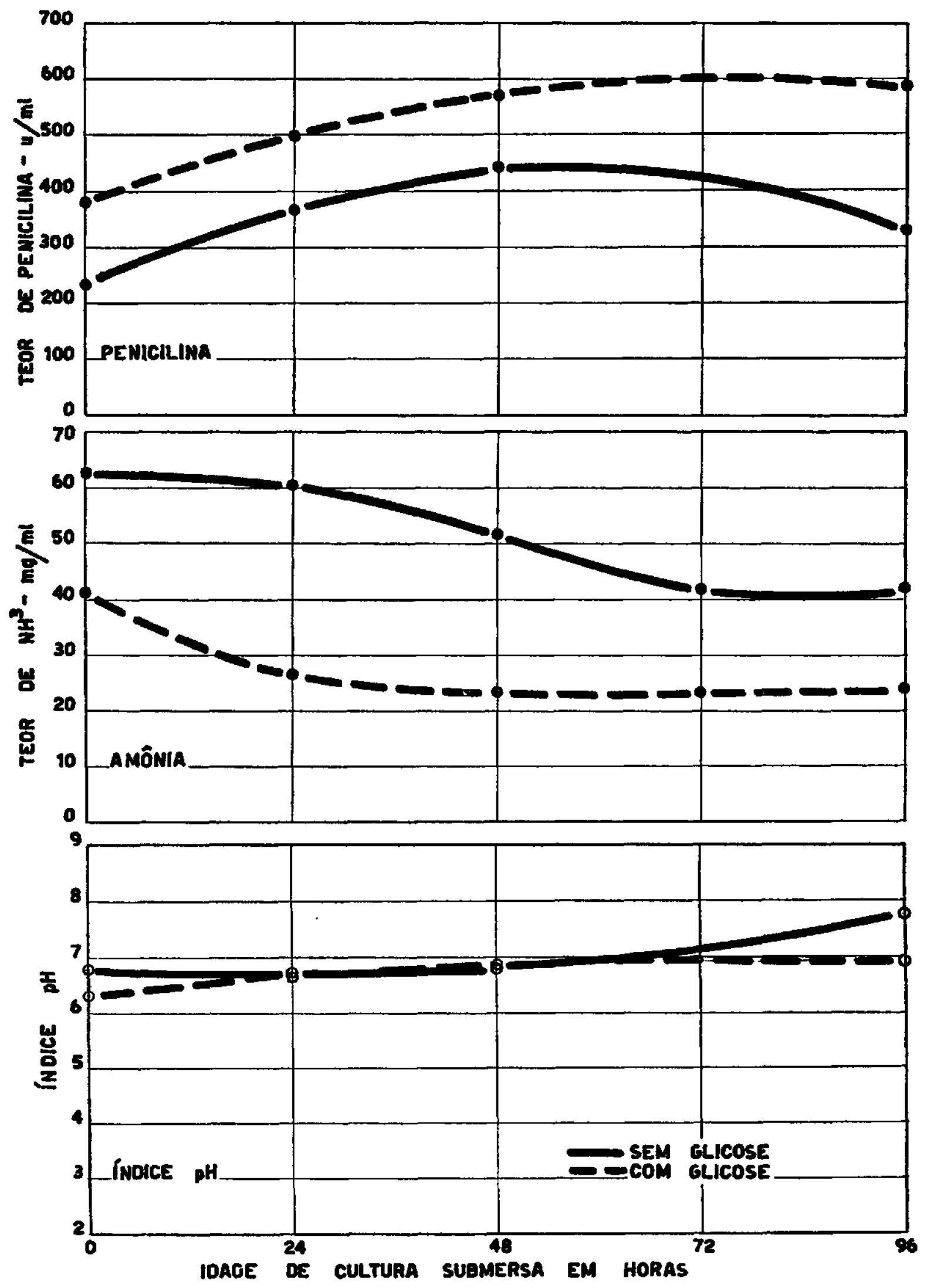

Frgura 1.-Variação dos teores de penicilina, amônia e do indice $\mathrm{pH}$, em diferentes fases do processo de fermentação contínua para produção de penicilina, em substratos com e sem glicose. 
por meio de culturas submersas de fungos. Os resultados obtidos evidenciaram a potencialidade destas culturas como agentes de sacarificação do amido de vários substratos utilizados nas destilarias de álcool etílico. Em virtude de não têrmos ainda concluído as investigaçóes sôbre o processo contínuo para produção de enzimas em culturas submersas de bolores, apresentaremos apenas um relato dos resultados obtidos até o momento.

0 processo utilizado originalmente para o cultivo submerso de bolor para obtenção de enzimas amilolíticas pode ser descrito, em linhas gerais, como segue :

A cultura submersa de Aspergillus niger Van Tieghem, estirpe n. ${ }^{\circ} 337$ do Northern Regional Research Laboratory, Illinois, EE. UU., é propagada a uma temperatura de $30^{\circ} \mathrm{C}$. $O$ substrato utilizado consiste em vinhaça filtra$\mathrm{da}\left({ }^{1}\right)$, à qual se adiciona de 1 a $3 \%$ de milho moído e $0,5 \%$ de carbonato de cálcio. Inicia-se a operação contínua cêrca de 48 horas após a semeadura do substrato com cultura pura de Aspergillus niger. Adotou-se na operação contínua um ciclo total de 48 horas. Denomina-se ciclo total o tempo necessário para retirar um volume total de cultura submersa igual ao volume total de substrato existente no propagador da cultura submersa. Um agitador tipo turbina é utilizado para provocar a dispersão do ar esterilizado introduzido para o arejamento da cultura. A agitação produz também uma uniformização do meio de cultura. Um arejamento satisfatório é obtido pela introdução de uma quantidade de ar igual a $1 / 4$ do volume total de meio existente no propagador, por minuto. Quando se trabalha com um grande volume de cultura submersa, $1 / 8$ de volume de ar, baseado no volume total de meio a arejar, é suficiente para produzir um bom arejamento. $O$ sistema consistiu em um único propagador e a duração da operação contínua foi limitada a cinco dias.

A análise das culturas submersas obtidas mostrou que as três enzimas, alfa-amilase, máltase e dextrinase limite $\left(^{2}\right)$ provàvelmente são as mais importantes na sacarificação do amido. Destas três enzimas, a máltase sofreu um decréscimo significativo em sua atividade durante a operação contínua (fig. 2). Verificou-se também que os mostos de cereais sacarificados com cultura submersa retirada, em dias consecutivos, do propagador que estava trabalhando em operação contínua, e depois fermentados, mostraram um decréscimo no rendimento alcoólico (fig. 3). Mostos sacarificados com culturas submersas do propagador que, havia 24 horas, estava trabalhando em operação contínua, apresentaram um rendimento alcó́lico de 5,5 p.g./bu. $\left({ }^{3}\right)$. Mostos sacarificados com culturas submersas do propagador que, havia 96 horas, estava trabalhando em operação contínua, apresentaram um rendimento alcob́lico de 4,8 p.g./bu. Êste decréscimo no rendimento alcó́lico se correlaciona com a idade da cultura submersa utilizada na sacarificação do mosto e está também em correlação com o decréscimo da

(1) Tradução da expressão inglêsa distillers'thin stillage.

(2) Tradução da expressão inglêsa limit dextrinase.

(3) Abreviação da expressão inglêsa proof gallons per bushel. Esta expressão indica a quantidade de álcool a $50 \%$ obtida de cada "bushel" de cereal fermentado. No caso citado, o rendimento foi de 5,5 galóes de álcool a $50 \%$, obtido de cada "bushel" de cereal fermentado. 


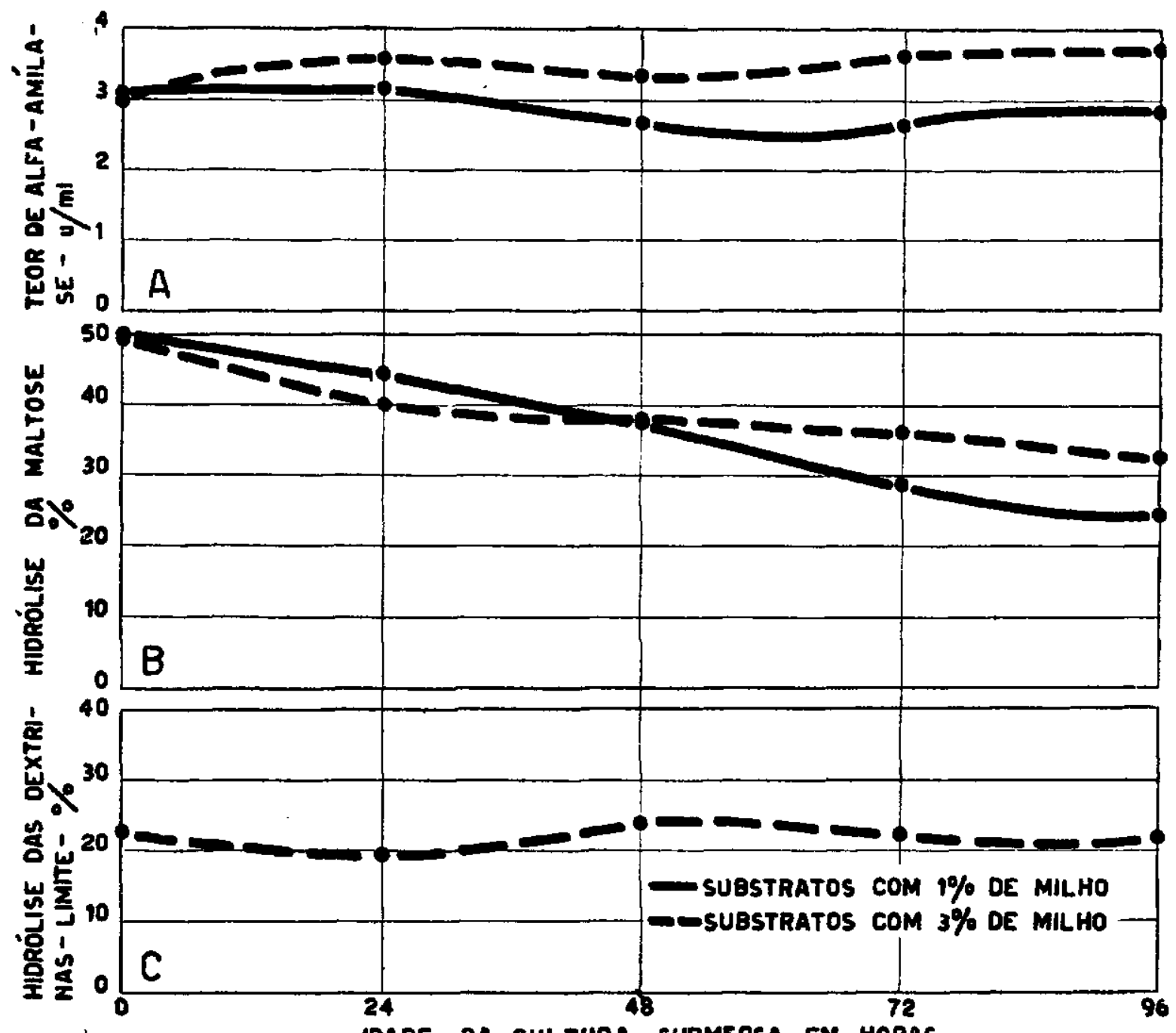

Frgura 2.-Variação do poder enzimático, em diferentes fases do processo de propagaçāo contínua de Aspergillus niger em substrato com $1 \%$ e $3 \%$ de milho. A-Únidades de alfa-amílase. $B$-Atividade da máltase (percentagem de maltose transformada em glicose). C-Atividade da dextrinase-limite (percentagem de dextrinas-limite transformada em glicose).

atividade da máltase nas culturas submersas retiradas, em dias consecutivos, do propagador trabalhando em operação contínua.

O decréscimo no rendimento alcoólico pôde ser atenuado pela modificação na composição do meio de cultura utilizado na propagação do bolor, bem como pela introdução de certas modificações na operação de cultivo do bolor. As modificações introduzidas consistiram em abaixar a temperatura de multiplicação do fungo para $25^{\circ} \mathrm{C}$ e em elevar a concentração de milho, no meio de cultura, utilizado para o cultivo do bolor. Mesmo assim, verificou-se um decréscimo no rendimento alcoólico dos mostos sacarificados com culturas submersas mais velhas, retiradas do propagador trabalhando em operação contínua (fig. 3). Entretanto, o rendimento alcoólico de mostos sacarificados com cultura submersa, retirada de um propagador, que estava trabalhando contìnuamente durante uma semana, foi ainda 


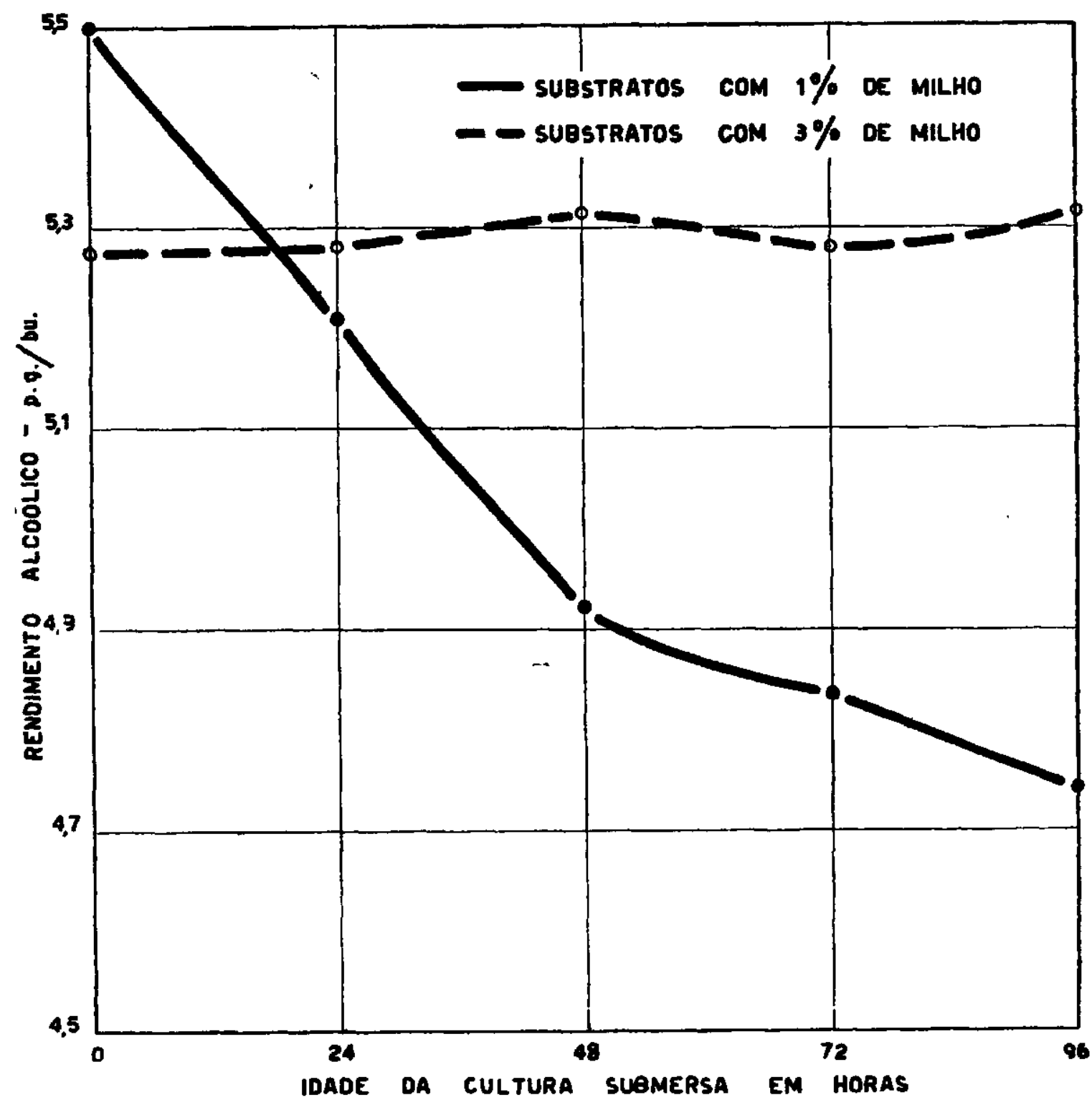

Figura 3.-Variação do rendimento alcoólico em mostos sacarificados por culturas submersas, obtidas em diferentes fases do processo de propagação contínua, usando substratos com $1 \%$ e com $3 \%$ de milho.

igual ao de mostos sacarificados com malte de cevada. Conclui-se, das experiências citadas, que o processo contínuo para produção de uma preparação enzimática não é um problema tão simples como possa parecer à primeira vista. E um problema muito mais complexo que o da produção contínua de penicilina, fermento ou álcool. O estudo das diversas enzimas, que atuam na sacarificação do amido, mostra maior correlação entre a atividade da máltase e o rendimento alcoólico. Não se pôde provar se a atividade da máltase é responsável, de per si, pela variação no rendimento alcoólico de mostos sacarificados com culturas submersas de bolores, ou se outros fatôres exercem também influência nesta variação no rendimento alcoólico. 


\section{4 - PRODUÇÃO DE ALCOOL ETIÍLICO}

Diversos processos foram investigados para a produção de álcool etílico em um sistema contínuo. Utilizamos em nossas experiências vários substratos e variamos também a aparelhagem empregada. Quando se realizou o 4. ${ }^{\circ}$ Congresso Internacional de Microbiologia, em 1947, apresentamos um trabalho referente a um processo de fermentação contínua de mostos de cereais, hidrolisados com ácidos minerais (27). Vamos relatar agora dois processos para a fermentação contínua de mostos de cereais sacarificados com culturas submersas de bolor e um outro processo para a fermentação contínua do melaço.

\section{1 - SACARIFICAÇÃO POR MEIO DE CULTURA SUBMERSA DE BOLOR}

Quando a sacarificação dos mostos de cereais é realizada por ação enzimática e o mosto sacarificado vai alimentar um sistema de fermentação contínua, a utilização de enzimas segregadas por fungos é a que oferece maiores vantagens. Estas preparaçōes enzimáticas podem ser obtidas em condições assépticas, e o processo para multiplicação do fungo 6 relativamente simples e econômico. $O$ emprêgo do malte não é recomendado, por se tratar de um produto que quase sempre contém certa percentagem de bactérias, bolores e outros microrganismos. A utilização do malte no sistema em operação contínua resultará numa multiplicação dêsses agentes contaminantes que certamente irão provocar fermentações indesejáveis com consequente redução no rendimento alcoólico. Além disso, o produto final resultante da fermentação nunca poderá ser uniforme.

As principais vantagens, oferecidas pelo uso de culturas submersas de fungos, são as seguintes : a) o preço de custo da operação de sacarificação é menor que o da sacarificação pelo malte ; b) substratos simples podem ser utilizados como meio de cultura para a multiplicação do fungo, constituindo um agente de sacarificação bastante viável nos países onde há escassez de bom malte ou onde o preço do malte seja excessivamente elevado; c) a operação de fermentação pode ser realizada assèpticamente, obtendo-se mostos livres de contaminantes ; d) a sacarificação é mais eficiente que pelo uso de malte de cevada; e) as culturas submersas de fungos possuem teor elevado de elementos nutritivos para o fermento alcoólico, possibilitando a preparação de mostos de substratos pobres em fatôres de crescimento para o fermento.

\section{2 - PROCESSO AMILO}

Realizamos experiências em que a sacarificação dos mostos de cereais foi conduzida pelo processo amilo (26). Os resultados obtidos foram comparados com os conseguidos em um outro processo de sacarificação que descreveremos mais adiante. $O$ sistema utilizado para o processo amilo consistiu em dois vasos, sendo que o primeiro recebeu o nome de pré-fermentador e o segundo de fermentador. A goma de cereal, não sacarificada, existente no pré-fermentador, é semeada com $10 \%$ (baseados no volume 
total de mosto a ser preparado) com cultura submersa de Aspergillus niger, estirpe NRRL-337. Após a adição da cultura submersa ao pré-fermentador, inicia-se a operação de arejamento por meio de dispersão mecânica. Por meio dêsse arejamento, obtém-se uma uniformização da goma, ao mesmo tempo que se oferecem condiçбes favoráveis para a secreção enzimática por intermédio do fungo. A goma de cereal sacarificada é transferida para o fermentador onde se processa a fermentação do mosto. $O$ uso dêste processo contínuo deu b́timos resultados. Apresentou, entretanto, duas desvantagens acentuadas : a) é necessário trabalhar com grande volume de mosto e, se houver contaminação, esta acarretará quebra no rendimento alcoólico; b) um tempo prolongado é necessário para preparar o mosto para a fermentação pròpriamente dita, incorrendo dêste modo num aumento do ciclo total de fermentação.

\section{3 - FERMENTAÇÃO DO MOSTO PELO PROCESSO "CONVENCIONAL"}

O processo para fermentação alcoólica em operação contínua, de mostos de cereais, que recebeu maior atenção em nosso laboratório foi aquêle por nós denominado processo do tipo "convencional". Neste processo, a produção de cultura submersa do fungo e a fermentação constituem operações independentes. Dêste modo, a sacarificação da goma de cereal pode ser realizada do mesmo modo que no processo comum de sacarificação pelo malte, isto é, a cultura submersa do fungo é adicionada à goma não sacarificada em operação que precede à fermentação.

O processo utilizado experimentalmente, até há pouco tempo, consistia na fermentação de mosto de milho sacarificado com $15 \%$ (baseados no volume total do mosto a preparar) de cultura submersa de Aspergillus niger, estirpe NRRL-337. Uma quantidade suficiente era preparada de modo que pudesse suprir o sistema para fermentação contínua pelo espaço de 24 horas. A fermentação contínua é realizada num sistema constituído por dois fermentadores. O primeiro fermentador, denominado fermentador primário, opera num ciclo de 18 horas, e nêle se processa a maior parte da fermentação, que é completada no fermentador secundário. No fermentador primário, o teor de açúcar do mosto cai de um valor inicial de cêrca de $12 \%$ para, aproximadamente, $2 \%$; a população de fermento permanece mais ou menos constante, variando entre 120-140 milhões de células por mililitro de mosto. Um período adicional de 18 horas é requerido para completar a fermentação do mosto no fermentador secundário.

Estudou-se também a influência da percentagem do agente sacarificante utilizado e do ciclo de fermentação sôbre o rendimento alcoólico. Sacarificamos mostos com 10,15 e 20\% (baseados no volume total de mosto a ser preparado) de cultura submersa de Aspergillus niger e, em seguida, os mostos obtidos foram fermentados durante 24,36 e 43 horas. Variou-se o período de fermentação pelo ajustamento do volume do mosto no fermentador secundário. Quando desejávamos um ciclo de fermentação mais curto, retirávamos uma quantidade maior de mosto no fermentador secundário, por unidade de tempo, de modo que o nível no fermentador secun- 


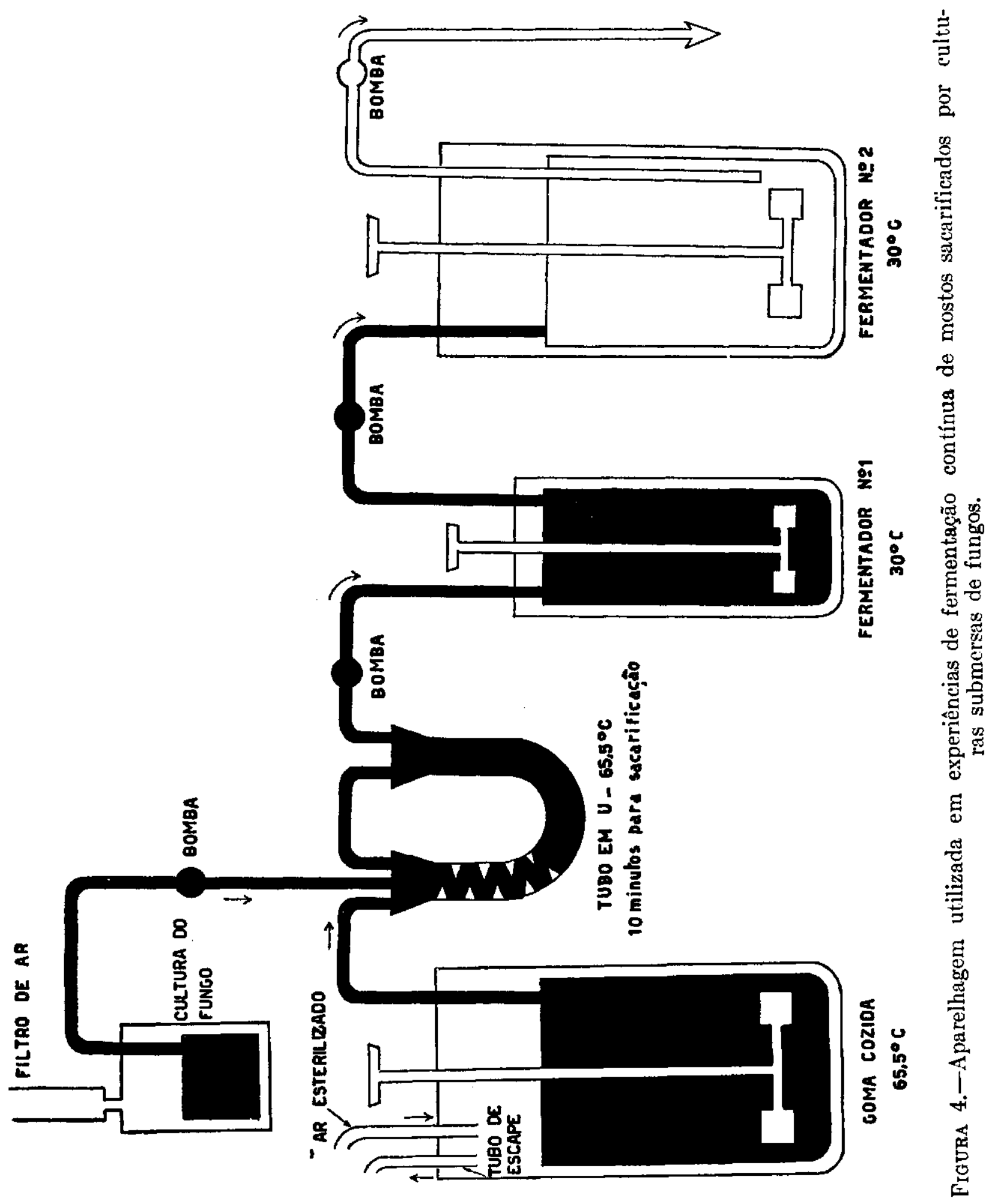


dário tende a baixar quando se trabalha com um ciclo de fermentação mais curto. A relação seguinte apresenta os rendimentos alcoólicos obtidos de mostos sacarificados com 10, 15 e $20 \%$ de cultura submersa de Aspergillus niger, utilizando-se ciclos de fermentação de 24, 36 e 43 horas.

Percentagem da culmura SUBMERSA UTILIZADA NA SACARIFICACGT̃O DA GOMA
Ciclo de fermentaç̃̃o EM HORAS

Rendimento alcoblico calculado sốbre a substancia original

$\begin{array}{lll}24 & \ldots \\ 36 & \ldots \ldots \ldots \ldots & 4,41 \\ 4 & & 4,64\end{array}$

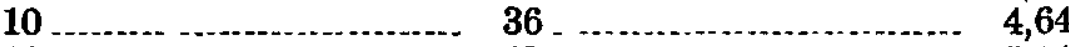

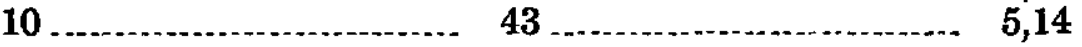

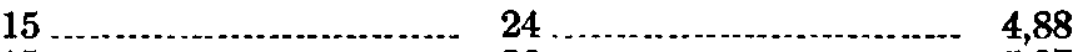

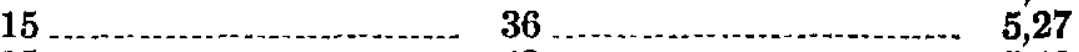

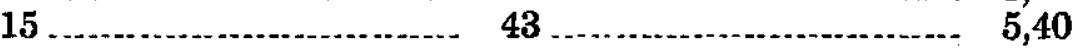

$20 \ldots \ldots \ldots \ldots$

$20 \ldots \ldots \ldots$ p.g./bu.

A fermentação mais rápida, e que deu rendimento alcoólico equivalente ao obtido na fermentação intermitente, de mostos sacarificados com malte, foi obtida pelo emprêgo de $15 \%$ de cultura submersa na sacarificação da goma e operando-se num ciclo total de fermentação de 36 horas. O rendimento alcoólico não aumentou, de maneira significativa, pela elevação da percentagem de cultura submersa utilizada na sacarificação da goma. Além disso, operando com um ciclo de fermentação de 36 horas, a fermentação foi incompleta, como evidencia o rendimento alcoólico muito mais elevado obtido de mostos operando com um ciclo de fermentação de 43 horas.

Em experiências mais recentes, o ciclo de fermentação de mostos de cereais sacarificados com $15 \%$ de cultura submersa de fungo foi reduzido, em virtude de melhoramentos introduzidos no processo, e pelo desenvolvimento de um método mais eficiente para a produção de culturas submersas. O equipamento melhorado está representado na figura 4 . O aparelhamento utilizado permite a alimentação simultânea de um tubo em $\mathbf{U}$ com goma não sacarificada e cultura submersa do fungo. Esta mistura permanece no tubo durante aproximadamente 10 minutos e, a seguir, é bombeada para o fermentador primário. O fermentador primário trabalha com um ciclo de 5 horas. O mosto em fermentação é transferido para o fermentador secundário, onde o ciclo de fermentação é regulado pela determinação do rendimento alcó́lico ótimo. Um ciclo total de 30 horas foi suficiente para se obterem rendimentos alcoólicos iguais aos obtidos posteriormente, quando se utilizou um ciclo de fermentação total de 36 horas. 0 ciclo de fermentação de 5 horas para o fermentador primário foi determinado por cálculos baseados nas curvas de multiplicação ou de crescimento (growth curves) do fermento alcoólico na fermentação intermitente, de acôrdo com o método de Adams e outros (21). Este ciclo permite manter a população de fermento constante e a um valor predeterminado.

Modificações no sistema de preparar a cultura submersa do fungo contribuíram bastante para reduzir o ciclo de fermentação; êstes melhoramentos já foram anteriormente mencionados. 


\section{4 - FERMENTAÇÃO DO MELAÇO}

O melaço é a matéria-prima utilizada, em grande escala, para a produção de álcool etílico. $O$ seu baixo preço e a relativa facilidade de se trabalhar com êle nos processos de fermentação têm sido os fatôres principais para torná-lo um competidor para as outras matérias-primas utilizadas na produção do álcool industrial. Entretanto, quaisquer melhoramentos que pudessem ser introduzidos no processo de fermentação do melaço, como, por exemplo, a redução do ciclo de fermentação, poderiam favorecer grandemente na utilização dêste subproduto da indústria açucareira nos processos de fermentação, tornando-o a fonte mais barata para obtenção de álcool.

Estudamos e desenvolvemos em nosso laboratório um processo contínuo para produção de álcool a partir do melaço (28). O melaço utilizado na fermentação é diluído com água, de modo que reduza o teor de açúcar para $12 \%$, e o pH é ajustado entre 4,0 e 4,5. Se o melaço fôr deficiente em nitrogênio ou fosfato, deve-se adicionar sulfato ou fosfato de amônio. $O$ melaço bruto cubano (Cuban blackstrap molasses) é melhor que o refinado ou do que o de beterraba, porque não é necessária a adição de sais nutritivos e, além disso, o ciclo de fermentação pode ser reduzido quando se usa êsse melaço.

O pé de fermentação é preparado por arejamento, sendo utilizada uma estirpe de Saccharomyces cerevisiz Hansen(1). As células são concentradas por centrifugação, e uma quantidade suficiente é adicionada ao fermentador de modo que se obtenha uma população inicial de cêrca de 350 milhóes de células por mililitro de mosto. Após um período de incubação estacionário, de cêrca de 5 horas, $91,5 \%$ do açúcar são utilizados, e a população de células de fermento se eleva a 550 milhóes por mililitro de mosto. Inicia-se a operação contínua e verifica-se ser possivel retirar até $25 \%$ do volume total do mosto do fermentador por hora, correspondendo a um ciclo total de fermentação de 4 horas. A temperatura ótima de fermentação foi de cêrca de $32^{\circ} \mathrm{C}$.

O pé de fermentação é adicionado sòmente no início da operação contínua. Os rendimentos alcoólicos obtidos por êste processo contínuo são equivalentes aos conseguidos pela fermentação intermitente do mesmo melaço num ciclo total de fermentação de 50 horas. As vantagens dêste processo são : a) grande redução no ciclo de fermentação; b) considerável redução no número e tamanho das dornas requeridas na operação de fermentação.

\section{5 - RESUMO E CONCLUSÕES}

Relatamos os resultados obtidos em nossas investigações sôbre processos de fermentação contínua, bem como experiências realizadas por outros pesquisadores. Estas investigaçбes demonstraram que o processo de fermentação contínua é bastante viável para a produção de álcool etílico.

(2) Estirpe n.ค 90 da coleçăo de Joseph E. Seagram \& Sons, Inc., obtida de melaço javanes. 
Os resultados obtidos demonstram também a praticabilidade da utilização de um processo contínuo para a produção de um número variado de produtos resultantes de fermentação, tais como fermento alimentício, antibióticos e enzimas. De maneira geral, o processo contínuo é tão econômico como o processo intermitente, com a vantagem de exigir aparelhagem mais reduzida ou, pelo menos, menor. A vantagem indiscutível do processo contínuo baseix-se no fato de ser possível um contrôle mais perfeito, assegurando, dêste modo, a obtenção de um produto mais uniforme em qualidade. Além disso, êsse processo elimina a possibilidade de se trabalhar em um sistema contaminado, o que constitui vantagem marcante na manutenção de um alto "standard" para a qualidade do produto.

\section{SUMMARY AND CONCLUSION}

The data which we have presented from some of our investigations and from those of other workers, show that a continuous fermentation process for the production of ethyl alcohol is feasible. This can be accomplished by using a variety of substrates and processes. The data also demonstrate the feasibility of continuous processing for the production of a variety of other fermentation products such as yeast, antibiotics and enzymes. Continuous processing, in general, is at least as economical as batch processing and usually requires less or smaller equipment. The indisputable advantage of continuous processing lies in the high degree of control which it makes possible, thereby insuring uniform quality of the product. In addition, a continuous processing precludes operation of a contaminated system - a distinct advantage in recovery and maintenance of quality standards.

\section{LITERATURA CITADA}

1. Anônimo. $E m$ Fiat Final Report n. 499 , Joint Intelligence Objective Agency, Washington, D. C., U.S.A., 1945.

2. Anônimo. Les usines de Melle et Boinot. Patentes canadenses n. ${ }^{\circ} 341.720,348.549$ e 402.847 .

3. Anônimo. Les usines de Melle et Boinot. Chem. Abst. 32 : 2683. 1938.

4. Sankey, C. A. e M. M. Rosten. Alcohol from waste sulfite liquor. Pulp \& Paper Mag. Can. 45 : 171.1944.

5. Ericsson, E. O. Alcohol from sulfite waste liquor. Pulp \& Paper Indus. 19 : 42. $19-5$.

6. Anônimo. Em Comercial fermentations, sem pg., Chemical Publishing Co., Inc., no prelo.

7. Fries, K. W. Sulfite waste utilization by Wisconsin plant. Lake States Timber Digest 2 : 6.1948.

8. Harris, E. E. e outros. Fodder yeast from wood hydrolyzates and still residues. Ind. Eng. Chem. 40 : 1220. 1948.

9. Harris, E. E. e outros. Production of food yeast from wood hydrolyzates. Ind. Eng. Chem. 40 : 2068. 1948.

10. Anônimo. Foor yeast production and utilization in Germany. Skagg Report U. S. Dept. Commerce, Office of Technical Service, Washington, D. C., U.S.A., sem data. 
11. Fritzweiler, R. e outros. Four years'working of wood saccharification at Tornesch. Chem. Abst. 31 : 7588. 1937. (Zeitung für Spiritusind. 59: 229. 1936).

12. Fritxweiler, R. e W. Karsch. Latest progress in wood saccharification according to the Scholler-Tornesch process. Chem. Abst. 33 : 1492. 1939. (Zeitung für Spiritusind. 61 : 207. 1938).

13. Schaal, O. Present status of the Scholler-Tornesch procedure for saccharification of cellulosic materials. Cellulose Chem. 16: 7. 1935.

14. Scholler, H. e R. Eichenmeyer. Die Gewinnung von Zucker, Spiritus und Futterhefe aus Holz als Rohstoff. Chem. Zeit. 60 : 293. 1936. (Patentes dos Estados Unidos da América do Norte n.os 2.083.347 e 2.083.348, 1934).

15. Scholler, H. e M. Seidel. Yeast production and fermentation. Chem. Abst. 34 : 3876. 1940. (Patente dos Estados Unidos da América do Norte n. ${ }^{\circ}$ 2.188.192, 1937).

16. Karsch, W. Alcohol production by fermentation. Chem. Abst. 33 : 5590. 1939 (Patente dos Estados Unidos da América do Norte n..$^{\circ}$ 2.155.134, 1939).

17. Ramage, W. D. e J. H. Thompson. Producing yeast from processing wastes. Em Yeasts in feeding, pg. 87-88, 1950, Milwaukee, Wisconsin, U.S.A.

18. Anônimo. Em Food yeast, Colonial Food Yeast, Ltd., Brook House, Londres, maio, 1944.

19. Veldhuis, M. K. U. S. Department Agric., Agric. Chem. Res. Div. Contrib. 222, sem data.

20. Veldhuis, M. K. e outros. Citrus Products Station, Winter Haven, U.S.A., não publicado.

21. Adams, S. L. A study of fermentation processes for the utilization of fruit wastes. Tese apresentada ao Washington State College, Pullman, U.S.A., 1949.

22. Whittier, E. O. e L. A. Rogers. Continuous fermentation in the production of lactic acid. Ind. Eng. Chem. 23 : 532. 1931.

23. Olive, T. H, Waste lactose is raw material for a new lactic acid process. Chem. and Met. Eng. 43 : 480. 1936.

24. Gerhardt, P. Brucella suis in aerated broth culture. Jour. Bact. 52 : 283. 1946.

25. Schneider, W. C. e outros. Laboratory continuous penicillin fermentation. Trabalho apresentado na 114." Reunião da "American Chemical Society", Estados Unidos da América do Norte. 1948.

26. Anônimo. Continuous production of amylolytic fungal enzymes by submerged cultivation. Relatórios não publicados de Joseph E. Seagram \& Sons, Inc., Louisville, Ky., Estados Unidos da América do Norte, 1948.

27. Ruf, E. W. e outros. Alcoholic fermentation of acid-hydrolyzed grain mashes. Ind. Eng. Chem. 40: 1154. 1948.

28. Bilford, II. R. e outros. Alcoholic fermentation of molasses. Ind. Eng. Chem. $34: 1406.1942$. 